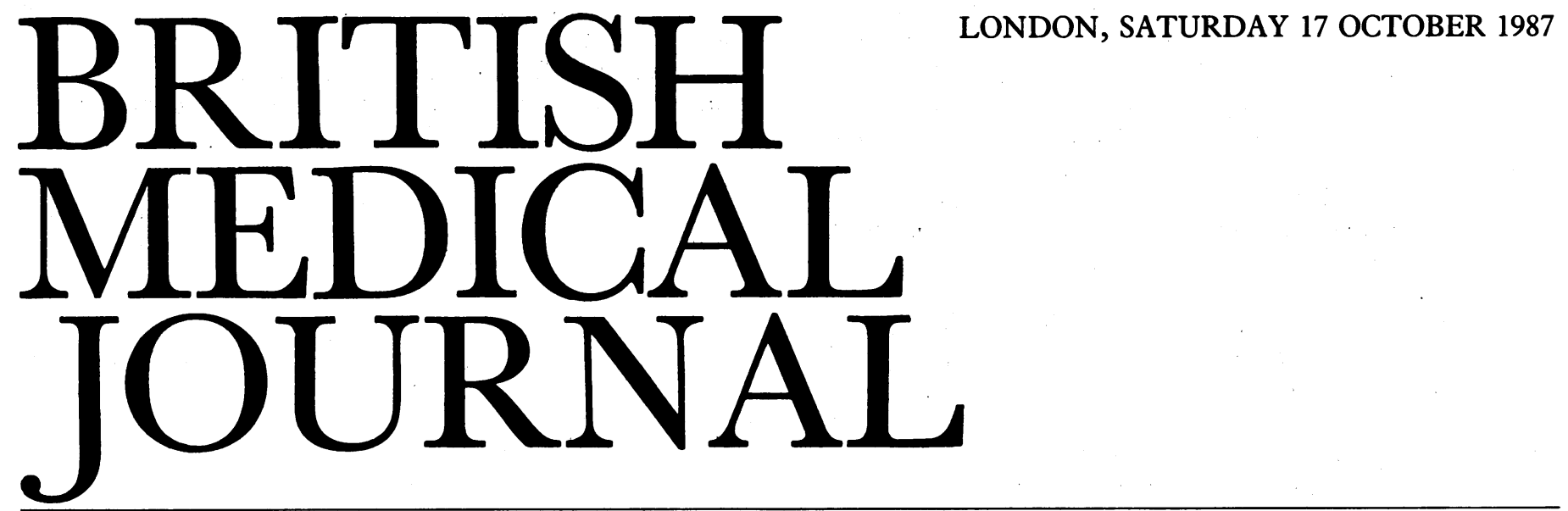

Next week parliament will debate health promotion. Ministers will seek to show that the public health is as "safe in their hands" as the health care service. They will be judged not by their rhetoric but by their actions, and when the Parliamentary Public Accounts Committee judged the performance of the Department of Health and Social Security last year it found it wanting. ${ }^{1}$ The department was severely criticised for its organisation and evaluation of preventive services.

By chance two days before the parliamentary debate the DHSS will be funding a conference on health promotion. A range of international experts will describe what can be achieved, often from a poor start, by combining political commitment, clear objectives, adequate long term funding, and coordinated public health measures. Ironically the speakers will include Mike Daube, director of health promotion in Western Australia and consultant to the World Health Organisation. Four years ago he was prevented by ministers from obtaining a senior post at the Health Education Council. The grounds for the veto were that he had offended commercial interests, initially as director of Action on Smoking and Health and later as honorary secretary of Action on Alcohol Abuse. His effectiveness worried those who put commercial profitability from tobacco, alcohol, and advertising above the public health.

Public health has faced great problems since the NHS was formed. Pragmatic political decisions biased the newborn NHS towards domination by hospital specialists, and not until the general practice charter of 1966 was priority given to primary care. The decline of the medical officer of health and the slow development of their successors in community medicine reduced the advocacy for prevention both among doctors and in the wider community. Parliament has enacted little public health legislation. Only a few acts stand outthose on clean air (1956), health and safety at work (1974), food and drugs (1955), consumer protection (1961), and specific measures such as drinking and driving, crash helmets, seat belts, and abortion. Politicians have often limited or delayed the advances in preventive medicine ${ }^{2}$ and even in Prevention and Health: Everybody's Business they tend to omit the job of government ${ }^{3}$; they concentrate on what people can do for themselves and ignore the need for environmental change and specific activity against agents that cause disease. Civil servants in the DHSS have little skill in public health as has been shown by the shallowness of some of their campaigns, the lack of education, and a failure of follow through. ${ }^{45}$ If the television programme Yes Prime Minister and the academic analysis by Baggott ${ }^{6}$ are correct, some key civil servants have been "domesticated" by the tobacco industry.

Within the NHS health promotion has not had any priority until recently, and funding remains a large problem, although the amount is minuscule in relation to clinical services. Medical teaching on health promotion has been poorly coordinated and ineffective. ${ }^{78}$ Local authorities, which used to take the lead in public health, have declined in importance, and key government departments-such as education, housing, agriculture, environment, trade, and the Treasury-have shown virtually no awareness of health. Thus grants have been given to promote employment in the tobacco industry and to develop smokeless tobacco teabags, which can be marketed to children; the Queen's Award for Exports has gone to tobacco companies for exports to the Third World; butter mountains have been created by agricultural policy in the European Community; alcohol and tobacco have been made cheaper relative to income; and the Department of Education has failed to emphasise health and exercise in its proposals for the national school curriculum.

Despite this systematic neglect of prevention, we think that cautious optimism on the future of health promotion may now be justified. Firstly, there is a remarkable degree of consensus about what needs to be done among public health professionals, epidemiologists, and bodies such as the World Health Organisation, the royal colleges, and the BMA. Secondly, health authorities, local authorities, educationalists, and the general public are becoming much more interested in health promotion. A survey reported today (p 1003) shows that more than three quarters of a large national sample of people wanted. health education to be given more importance in schools, no smoking areas to be provided in all public places, and a ban on smoking in NHS hospitals and premises; and more than two thirds wanted the advertising and promotion of tobacco to be banned.

Thirdly, the present health ministers, who seem genuinely 
committed to health promotion, have included health promotion in recent NHS regional reviews, and this impetus is now spreading through the service to district and unit reviews. They have also strongly supported the World Health Organisation's strategy for Health For All 2000.910 Outside the DHSS the Prime Minister has shown concern for inner cities, though the health effects of some of her other policies may last for generations by further widening the health divide; and the Home Secretary has established a standing interdepartmental ministerial committee to combat alcohol misuse."

On the professional side, the Faculty of Community Medicine last year woke up to its opportunities and responsibilities and published its Charter for Action on Health for All 2000. ${ }^{12}$ Elsewhere among health professionals there is greater awareness of health promotion, better coordination and planning, and increasing pressure for action on smoking, ${ }^{13-15}$ nutrition and coronary heart disease, ${ }^{16}$ and alcohol abuse. ${ }^{17-20}$ There is also greater professionalism among health educators and increasing skill in evaluation, ${ }^{21}$ although the science, planning, activities, and evaluation of what happens in some districts leaves much to be desired. The Health Education Authority, despite the public relations disasters surrounding its birth, now has a central place in the structure of the NHS that can be built on if the "sturdy independence" claimed by its new chief executive truly exists.

What then needs to be done? Both houses of parliament must endorse the Health For All by the Year 2000 strategy, allocate time to consider the recommendations for legislation, and ensure that in future opportunities exist to consider the health consequences of legislation. The Prime Minister should require all government departments to identify and review policies that may affect health. The chancellor should consider how fiscal policy can be used to promote health, and the DHSS should give greater priority to developing policy for health promotion and implementing and evaluating existing policy. The advice to other government departments should be augmented, and indefensible policies that bring international disgrace on British public health $^{22}$ - such as the voluntary agreement on tobacco advertising and sponsorship-should end.

The NHS Management Board should make it clear that health promotion is to be the local priority, ensure that new resources are made available, and clarify the job of the Health Education Authority in relation to the rest of the NHS. The Health Education Authority and the NHS Training Authority must improve the quality and effectiveness of health promotion. The Medical Research Council should consider establishing two or three multidisciplinary units to work in health promotion. The job of the regional health authorities will depend on the arrangements agreed for the Health Education Authority, but they should at least provide multidisciplinary advice and monitor district activities.

Much health promotion must go on in health districts, which require resources and long term commitment from the authorities and better collaboration with other statutory and voluntary agencies. The detailed monitoring arrangements in districts will be heavily dependent on the outcome of the Acheson inquiry on the public health, but the district medical officer should be confirmed as responsible for improving the quality of the health environment and preventive services. The right and duty of unfettered but professionally sound public speech on matters affecting public health should be emphasised. Health education departments must be given proper resources, and doctors need to improve their preventive activities.
But action from the bottom will never be fully effective without support from the top. Doctors must seek to persuade their members of parliament of the importance of political action on health. Perhaps this would effectively counter the seductive and extensive lobbying of groups like the tobacco industry.

Hampstead Health Authority, Royal Free Hospital, London NW3 2QG

NOEL D L OLSEN District medical officer

Health Education Service,

Riverside Health Authority, London SW1P 4NB

1 Committee of Public Accounts. Preventive medicine. London: HMSO, 1986. (44th Report.)

2 Harrow A. Politics, society and preventive medicine. A review. London: Nuffield Provincial Hospitals Trust, 1986. (Occasional Paper No 6.)

3 Health Departments of Great Britain. Prevention and health: everybody's business. London: HMSO, 1976

4 Olsen NDL. Look after your heart. Br Med $\mathcal{F}$ 1987;294:1115.

5 Dillon A. Why are we concerned? The Coronary Prevention Group response to the Look After Your Heart Campaign. London: Faculty of Community Medicine, Royal College of Physicians, 1987.

6 Baggott R. Government/industry relations in Britain: the regulation of the tobacco industry. Policy and Politics 1987;15:137-46.

7 Department of Health and Social Security. Alcohol related problems in undergraduate medical education. A survey of English medical schools. London: DHSS, 1987.

8 Department of Health and Social Security. Alcohol related problems in higher professional and postgraduate medical education. London: DHSS, 1987.

9 World Health Organisation. Assembly resolution WHO 30 43. Geneva: WHO, 1977.

10 World Health Organisation Europe. Targets for health for all: targets in support of the European regional strategy for healih for all. Copenhagen: WHO Regional Office for Europe, 1985.

11 Smith R. Action on alcohol abuse-at last. Br Med $\mathcal{Y}$ 1987;295:740.

12 Faculty of Community Medicine. Charter for action: health for all 2000. London: Faculty of Community Medicine, Royal College of Physicians, 1986.

13 Royal College of Physicians. Health or smoking. London: Pitman, 1983.

14 Olsen NDL, Roberts J, Castle P, eds. Smoking prevention. A health promotion guide for the NHS London:-Action on Smoking and Health and Health Education Council, 1981.

15 Crofton J, Wood M. Smoking control: strategies and evaluation in community and mass medie programmes. London, Belfast, Edinburgh: Health Education Council, Ulster Cancer Foundation, Scottish Health Education Group, 1986.

16 Rose G, chairman. Coronany heart disease prevention: plans for action. London: Pitman, 1984.

17 Royal College of General Practitioners. Alcohol: a balanced view. London: RCGP, 1986.

18 Royal College of Physicians. A great and growing evil: the medical consequences of alcohol abuse. London: Tavistock 1987.

19 Royal College of Psychiatrists. Alcohol, our favourite drug. London: Tavistock, 1986.

20 Tether P, Robinson D. Preventing alcohol problems: a guide to local action. London: Tavistock, 1986.

21 Evered D, Whelan J, eds. The value of preventive medicine. London: Ciba Foundation, 1985. (Ciba Foundation Symposium No 110.)

22 Proboscis. International interaction. The Health Services 1987 September 11.

\section{What was the matter with Dr Spooner?}

W A Spooner (1844-1930), fellow and warden of New College, Oxford, was an albino. He has become immortalised by his transposition of the initial sounds of words (spoonerisms), and his dysgraphia and dyspraxia have been described in detail. ${ }^{1}$ Were they related to his albinism?

Our understanding of albinism has advanced appreciably in recent years. Depending on how their hairbulbs respond to incubation with tyrosine, complete and incomplete universal albinos are now called tyrosinase negative and tyrosinase positive oculocutaneous albinos ${ }^{2}$; and several other rarer forms of oculocutaneous albinism have recently been described. ${ }^{3}$ Not all ocular albinos have the classical X linked form of the disease described early this century4: 